Article

\title{
Tensile and Shear Mechanical Characteristics of Longmaxi Shale Laminae Dependent on the Mineral Composition and Morphology
}

\author{
Lihui Li ${ }^{1,2,3, *(\mathbb{C})}$, Beixiu Huang ${ }^{1,2,3}$, Xiaolin Huang ${ }^{1,2,3}$, Ming Wang ${ }^{1,2,3}$ and Xiao Li ${ }^{1,2,3}$ \\ 1 Key Laboratory of Shale Gas and Geoengineering, Institute of Geology and Geophysics, Chinese Academy \\ of Sciences, Beijing 100029, China; huangbeixiu@mail.iggcas.ac.cn (B.H.); \\ huangxiaolin@mail.iggcas.ac.cn (X.H.); wangming@mail.iggcas.ac.cn (M.W.); lixiao@mail.igcas.ac.cn (X.L.) \\ 2 College of Earth and Planetary Science, University of Chinese Academy of Sciences, Beijing 100049, China \\ 3 Innovation Academy for Earth Science, Chinese Academy of Sciences, Beijing 100029, China \\ * Correspondence: 1hli2942@mail.igcas.ac.cn
}

Received: 4 May 2020; Accepted: 8 June 2020; Published: 10 June 2020

check for updates

\begin{abstract}
Laminae are well developed in shale and generally influence fracture propagation during hydraulic fracturing. Hence, comprehensively understanding the tension and shear behaviors of shale laminae is crucial. There have been limited systematic studies thus far on the tensile and shear strength as well as fracture morphology of shale laminae. In this study, the Lower Silurian Longmaxi Shale (China) was investigated via Brazilian tensile and angle-varied plate shear tests. Five lamina types were tested, i.e., calcite (Cal), pyrite (Py), organic-enriched (Oc), the interface between Cal and Oc (Cal-Oc), and the interface between Py and Oc (Py-Oc) laminae. Results showed that the tensile strength was in the range 0.43-8.22 MPa, mainly in the order of $\mathrm{Cal}>\mathrm{Py}>\mathrm{Cal}-\mathrm{Oc}>\mathrm{Py}-\mathrm{Oc}>\mathrm{Oc}$. The modes of fracture morphology were highly related to the occurrence, continuity, and mineralogy fillings of laminae. Shear strength parameters were within the range 22.50-29.64 MPa for cohesion and $37.29-43.60^{\circ}$ for internal friction angle. Fracture surface roughness was strongly related to its cohesion. Calcite laminae considerably influenced the tensile fracturing of shale, suggesting that the geometry and properties of calcite lamina should receive more attention during the design of shale gas exploration.
\end{abstract}

Keywords: shale laminae; tensile strength; shear strength characteristics; fracture morphology; Longmaxi Shale (China)

\section{Introduction}

Shale is generally characterized by layered structures and consequent intrinsic anisotropy owing to distinct sequential sedimentation [1]. The frequently developed sandy laminae in shale have a significant influence on the accumulation [2], storage, and permeability [3] of shale gas as well as on the mechanical properties of shales [4,5]. Outcrop observation and core analysis have indicated that black shale deposited in marine environments was abundant with calcite-/pyrite-rich laminae and lenses as well, such as the Longmaxi Shale [6] and the Devonian Horn River Shale [7]. Calcite and pyrite within shale are generally regarded as brittle minerals and classified into the calcite group and quartz group respectively, which can enhance the brittleness of shale and make the shale more likely to generate and maintain fractures when stimulated [8,9].

Quantitative moduli mapping of organic and inorganic components in shale at a nanometer scale demonstrated that the Young's modulus of different components is distinguishable and varies significantly, ranging from $15 \mathrm{MPa}$ for organic matter to nearly $100 \mathrm{MPa}$ for quartz, except for pyrite being the stiffest in the range 250-312 MPa [10,11]. The heterogeneity of mineralogical components is a 
key factor controlling the mechanical property of the shale. Overall, the static Young's modulus and dynamic modulus of shale decrease monotonically by increasing the content of clay plus kerogen $[12,13]$. Shale with a higher fraction of carbonate, biogenic quartz, or pyrite is relatively brittle, whereas the clay-rich laminated and bioturbated shale are more ductile [14]. However, these studies focused on the correlation between mineral composition-based brittleness and the elastic property of shales, such as Young's modulus and Poisson's ratio $[8,15]$. Few investigations are available for the strength heterogeneity of interbedded laminae in shale, such as the calcite-/pyrite-rich laminae, even though these laminae are widely spread in some shales.

Tensile strength is a critical parameter for determining the load-bearing capacity and crushing process of rock since its mechanical characteristic is generally considerably weaker under tensional conditions than in compressional [16]. The tensile strength of the Green River Shale under Brazilian conditions exhibits a good negative correlation with total organic carbon (TOC) [17]. Nevertheless, a few researchers [18] have commented that there was no evident correlation between the tensile strength and the mineral content of carbonates or clay and mica for the Lower Cambrian Niutitang Shale and the Lower Silurian Longmaxi Shale. Shear strength is another key mechanical property, as the compression-induced tensile and shear fractures are two fundamental fracture types in rock fracturing tests [19]. The angle-varied plate shear test is a prevalent experimental method to analyze the shear strength of rock joints and rocks [20-22]. Abousleiman [23] developed an innovative inclined direct shear test and examined the shear strength and stress-dependent elastic modulus of the Woodford Shale. Frash [24] conducted high-stress triaxial direct-shear fracturing on the Utica Shale to investigate the variation in apparent permeability and fracture geometry during the fracturing process using in-situ X-ray microtomography. However, these relative studies focused on the mechanical properties of the whole shale influenced by mineral composition. Regarding the mechanical response of laminae in shale, few publications are available, even though it is well known that lamination considerably influences the trace of fracturing cracks in shale.

This study aims to explore the tensile strength, shear strength, and fracture morphology of shale laminae considering different mineral components. The tensile and shear mechanical properties were investigated via Brazilian tensile and the angle-varied plate shear tests on shale samples considering five types of laminae. The fracture pattern and surface topography were observed subsequently and characterized quantitatively. The tensile and shear strength and fracture modes of laminated shales could provide a scientific basis to understand and optimize the complex fracture network within brittle laminae.

\section{Materials and Methods}

The laminated marine shale was sampled from the typical outcrop of the Longmaxi Shale Formation, Sichuan Basin, Shizhu County, Chongqing city, southwestern China (Figure 1). This zone has been targeted as the main shale play for marine shale gas exploitation $[25,26]$. First, cylindrical cores with a diameter of $50 \mathrm{~mm}$ and cuboid cores with a length of $30 \mathrm{~mm}$ were processed from larger shale cubes in the direction parallel to the laminae. The disc-shaped specimens with a diameter of $50 \mathrm{~mm}$ and a thickness of $25 \mathrm{~mm}$ as well as the cubes with a length of $30 \mathrm{~mm}$ were then processed. All the end surfaces were ground until smooth. The center regions of discs and the medial cross-sections of cubes were set with one of five types of laminae or interfaces, i.e., calcite lamina (Cal), pyrite lamina (Py), organic-enriched lamina (Oc), the interface of $\mathrm{Cal}$ and Oc lamina (Cal-Oc), and the interface of Py and Oc lamina (Py-Oc) (see Figures 2 and 3). A total of 25 disc specimens $(\Phi 50 \mathrm{~mm} \times 25 \mathrm{~mm}$ ) for the Brazilian tensile tests and 25 cubic samples $(30 \mathrm{~mm} \times 30 \mathrm{~mm} \times 30 \mathrm{~mm}$ ) for the angle-varied plate shear tests were prepared, with five samples for each lamina or interface, respectively. 


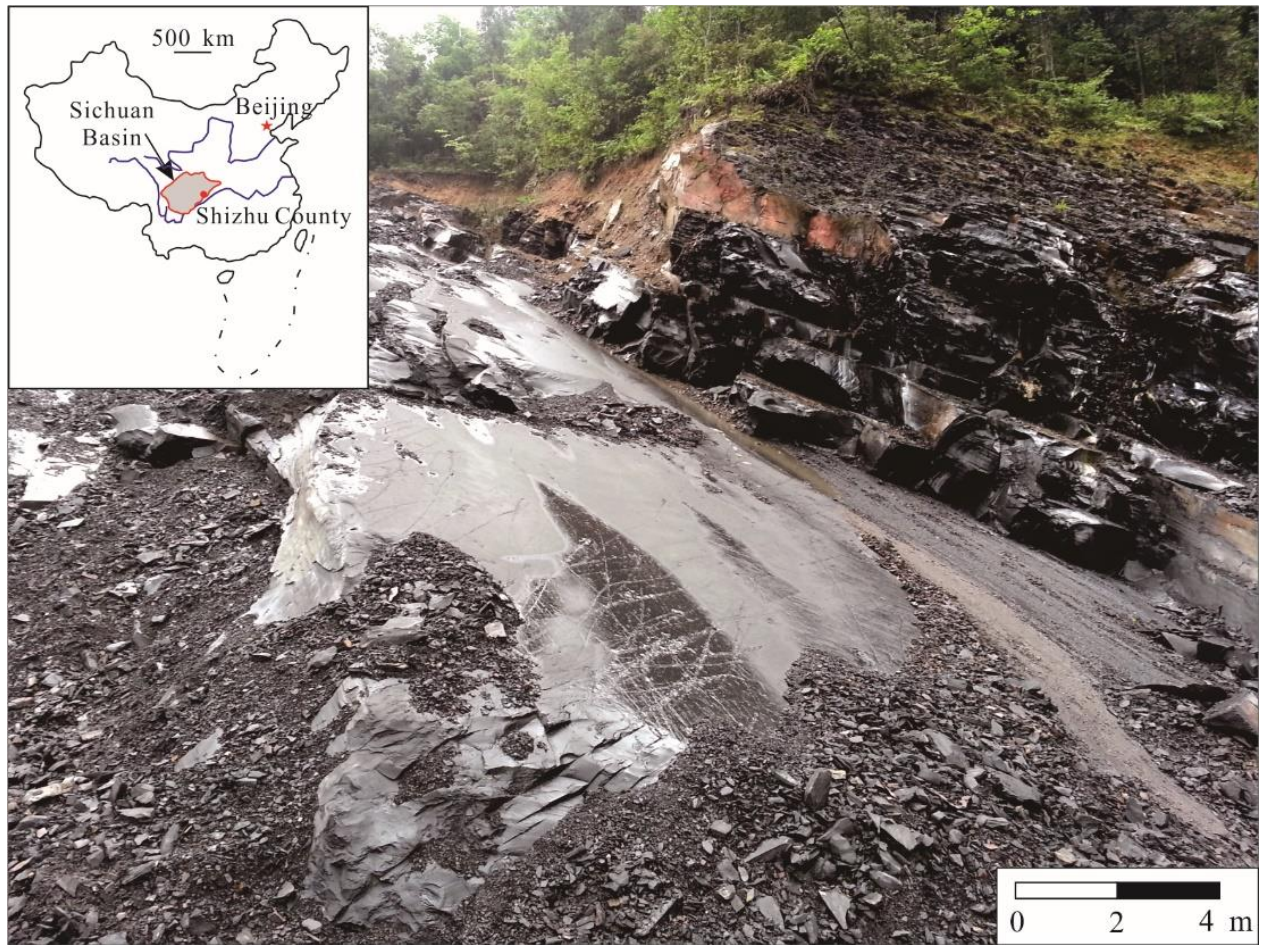

Figure 1. Location site and outcrop of the Longmaxi Shale in Shizhu County, Sichuan Basin, China.
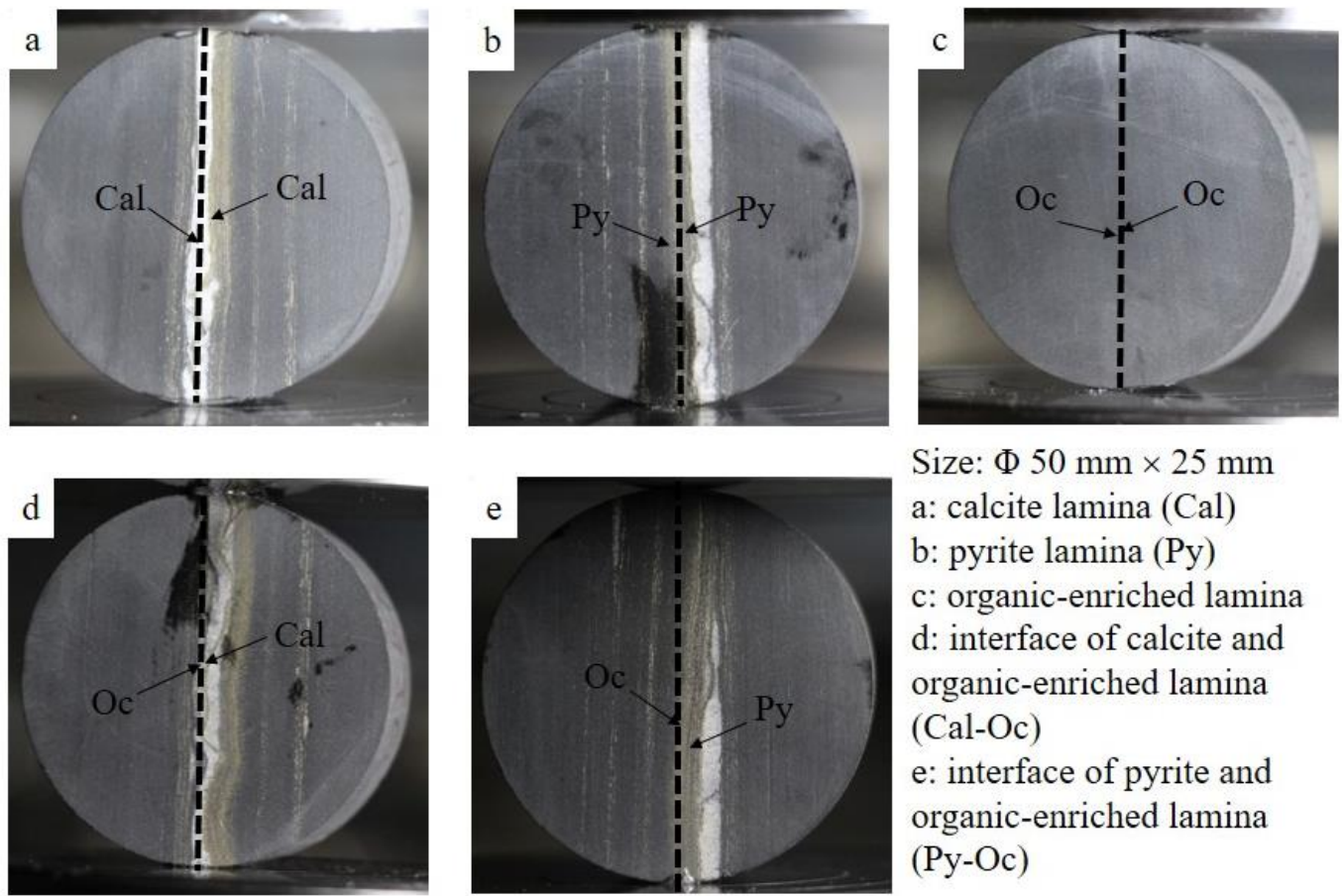

Size: $\Phi 50 \mathrm{~mm} \times 25 \mathrm{~mm}$ a: calcite lamina $(\mathrm{Cal})$ b: pyrite lamina (Py) c: organic-enriched lamina $\mathrm{d}$ : interface of calcite and organic-enriched lamina (Cal-Oc)

e: interface of pyrite and organic-enriched lamina (Py-Oc)

Figure 2. Brazilian discs prepared with various laminae. 

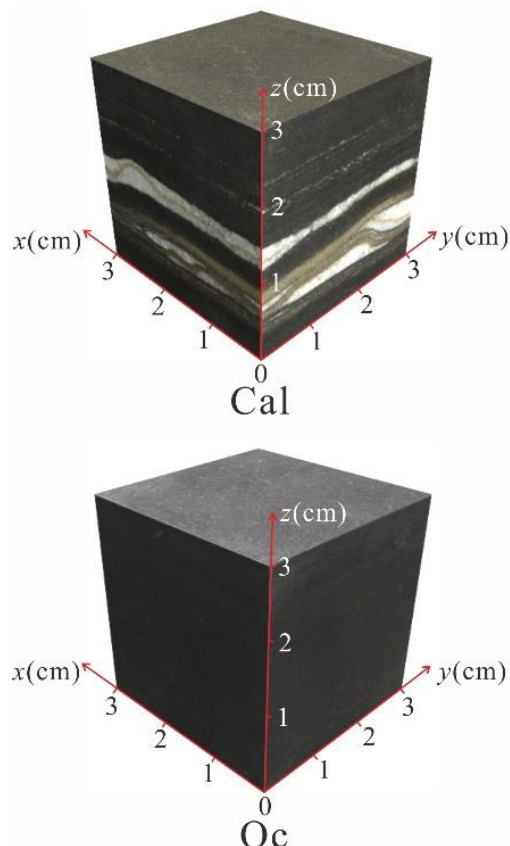

$\mathrm{Oc}$

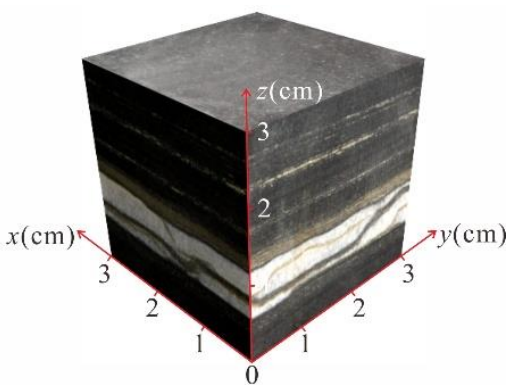

Py

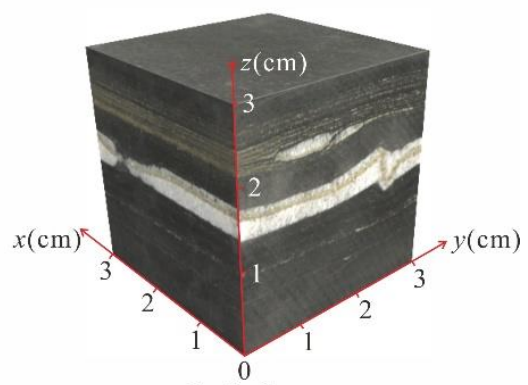

Cal-Oc

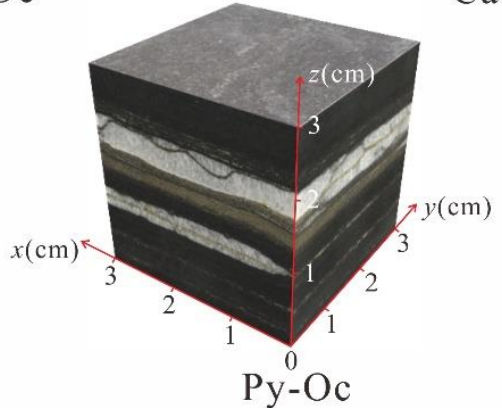

Figure 3. Cubic specimens prepared with various central laminae.

The microcomputer-controlled electronic universal testing machine MTS-SANS CMT integrated with three sets of shear clamps (see Figure 4) was employed to conduct the Brazilian tensile and angle-varied plate shear tests. Disc samples were loaded at a constant velocity of $0.06 \mathrm{~mm} / \mathrm{min}$ until failure, while cubic samples were loaded at a constant loading rate of $1 \mathrm{kN} / \mathrm{s}$, with the inclination angle of shear clamps varying from $20^{\circ}, 30^{\circ}$, and $40^{\circ}$. Images of the specimens with various laminae before and after Brazilian tensile tests were taken using cameras for a fracture morphology analysis. Meanwhile, the fracture surface roughness of broken cubic specimens was measured using the combination of a high-resolution stereo microscope M205A and a Leica Map Start software module. 

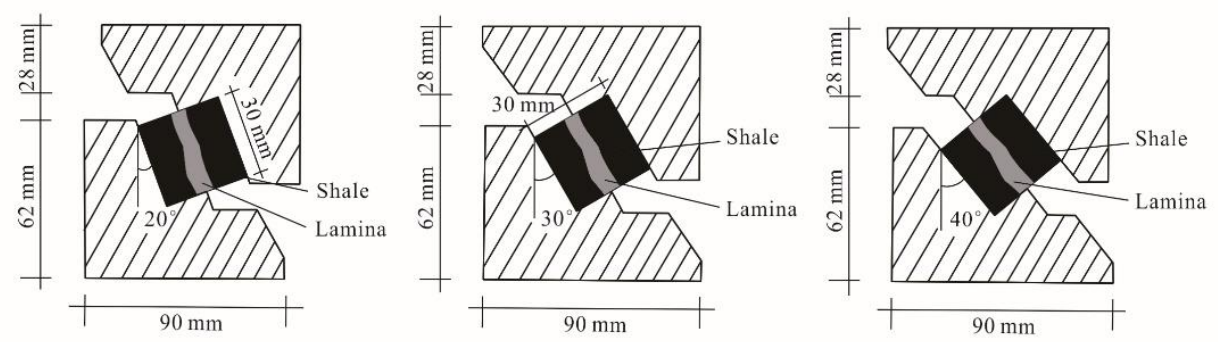

(a) Angle-varied plate shear tests
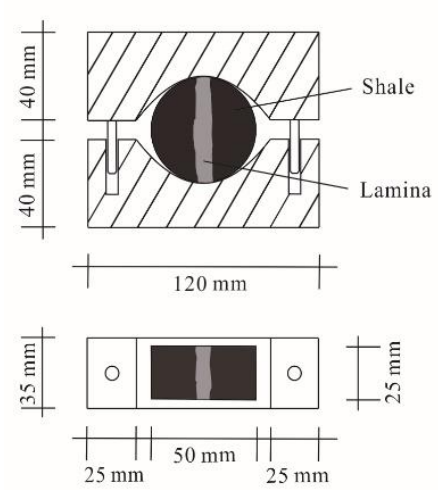

(b) Brazilian tests

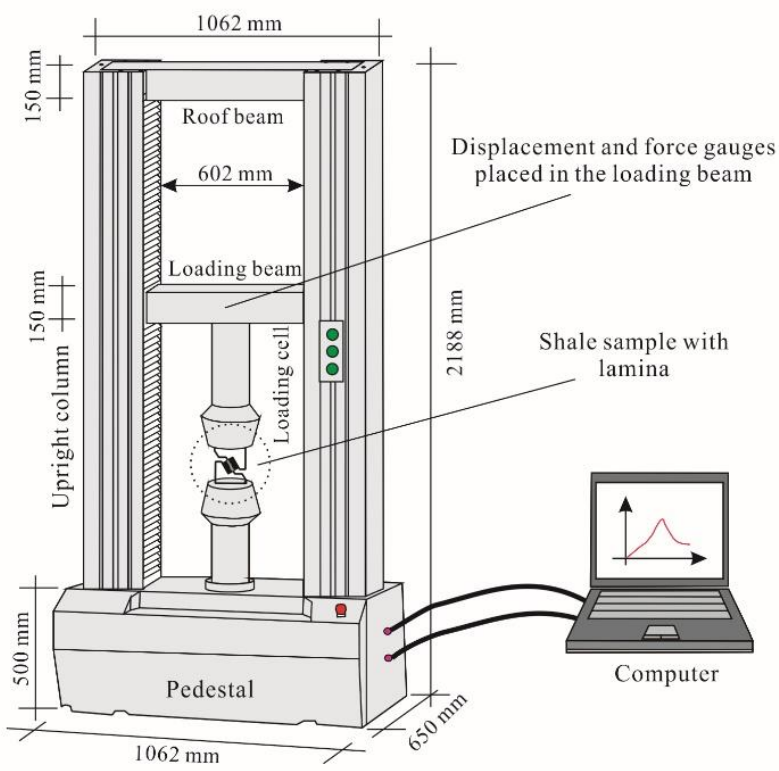

(c) Loading system

Figure 4. Apparatus used for mechanical tests. (a) Shale samples with laminae for angle-varied plate shear tests. (b) Shale samples with laminae for Brazilian tests. (c) Loading system of microcomputer-controlled electronic universal testing machine MTS-SANS CMT.

\section{Results}

\subsection{Tensile Strength}

As recommended by the International Society for Rock Mechanics, the tensile strength was calculated as follows [27]:

$$
\sigma_{\mathrm{t}}=2 P / \pi D t=0.636 P / D t
$$

where $\sigma_{\mathrm{t}}$ is the tensile strength $(\mathrm{MPa}), P$ is the load at failure $(\mathrm{N}), D$ is the diameter of the test specimen $(\mathrm{mm})$, and $t$ is the thickness of the specimen measured at the center $(\mathrm{mm})$.

Equation (1) was derived for isotropic materials assuming that the specimen failed with a vertical fracture along the loading diameter. Because the typical vertical splitting failure of a disc cannot be fully achieved for transversely isotropic rock material, in this study, the calculated "tensile strength" is set into quotation marks, referring to the maximum tensile stress at the center of the disc specimen once the specimen has lost its total sustaining capacity [28]. Consequently, the formula was adopted only for comparison among specimens with various laminae; further, the results need not characterize the true tensile strength of the samples [29].

The original test numbers BFW01-05, BHW01-05, BYW01-05, BFY01-05, and BHY01-05 named on samples corresponds to the five sample types with laminae of Cal, Py, Oc, Cal-Oc, and Py-Oc, respectively. Therefore, we substituted the original numbers with Cal01B-05B, Py01B-05B, Oc01B-05B, Cal-Oc01B-05B, and Py-Oc01B-05B to make the consequent analysis clearer and easier to compare. 
Tensile strengths obtained from the Brazilian tensile tests were in the range 0.43-8.22 MPa for shale with different laminae, as listed in Table 1. Since the occurrence of laminae has unavoidable differences with that of design, the tensile strength varied considerably even if the specimen were within those of the same central laminae type. In general, the shale specimens with calcite/pyrite laminae (Cal/Py) had the highest tensile strength, approximately $6 \sim 8 \mathrm{MPa}$, followed by specimens with the interface of calcite/pyrite laminae and organic-enriched laminae (Cal-Oc/Py-Oc) $(2 \sim 6 \mathrm{MPa})$, and the lowest tensile strength (0.43-1.66 MPa) was measured in shale with organic-enriched laminae (Oc).

Table 1. Tensile strength of the Longmaxi Shale with various tested laminae in the center of discs.

\begin{tabular}{|c|c|c|c|c|c|c|}
\hline $\begin{array}{c}\text { Laminae } \\
\text { Type }\end{array}$ & $\begin{array}{c}\text { Designed } \\
\text { Sample } \\
\text { Number }\end{array}$ & $\begin{array}{l}\text { Designed } \\
\text { Tensile } \\
\text { Strength } \\
\text { (MPa) }\end{array}$ & $\begin{array}{c}\text { Average } \\
\text { Designed } \\
\text { Tensile } \\
\text { Strength } \\
\text { (MPa) }\end{array}$ & $\begin{array}{l}\text { Realigned } \\
\text { Sample } \\
\text { Number }\end{array}$ & $\begin{array}{l}\text { Realigned } \\
\text { Tensile } \\
\text { Strength } \\
\text { (MPa) }\end{array}$ & $\begin{array}{c}\text { Realigned } \\
\text { Average } \\
\text { Tensile } \\
\text { Strength } \\
\text { (MPa) }\end{array}$ \\
\hline \multirow{5}{*}{ Cal } & Cal01B & 6.56 & \multirow{5}{*}{6.81} & Cal03B & 6.95 & \multirow{5}{*}{7.39} \\
\hline & Cal02B & 5.31 & & Cal04B & 8.22 & \\
\hline & Cal03B & 6.95 & & Cal05B & 7.00 & \\
\hline & Cal04B & 8.22 & & Cal-Oc05B & 6.96 & \\
\hline & Cal05B & 7.00 & & Py-Oc05B & 7.83 & \\
\hline \multirow{5}{*}{ Py } & Py01B & 2.94 & \multirow{5}{*}{5.47} & Cal01B & 6.56 & \multirow{5}{*}{6.35} \\
\hline & Рy02B & 6.09 & & Рy02B & 6.09 & \\
\hline & Py03B & 6.45 & & Рy03B & 6.45 & \\
\hline & Py04B & 5.45 & & Py05B & 6.42 & \\
\hline & Py05B & 6.42 & & Cal-Oc03B & 6.23 & \\
\hline \multirow{5}{*}{ Cal-Oc } & Cal-Oc01B & 5.58 & \multirow{5}{*}{5.95} & Cal02B & 5.31 & \multirow{5}{*}{5.47} \\
\hline & Cal-Oc02B & 6.00 & & Py04B & 5.45 & \\
\hline & Cal-Oc03B & 6.23 & & Cal-Oc01B & 5.58 & \\
\hline & Cal-Oc04B & 4.99 & & Cal-Oc02B & 6.00 & \\
\hline & Cal-Oc05B & 6.96 & & Cal-Oc04B & 4.99 & \\
\hline \multirow{5}{*}{ Py-Oc } & Py-Oc01B & 3.72 & \multirow{5}{*}{4.67} & Py01B & 2.94 & \multirow{5}{*}{3.69} \\
\hline & Py-Oc02B & 3.36 & & Py-Oc01B & 3.72 & \\
\hline & Py-Oc03B & 4.42 & & Py-Oc02B & 3.36 & \\
\hline & Py-Oc04B & 4.01 & & Py-Oc03B & 4.42 & \\
\hline & Py-Oc05B & 7.83 & & Py-Oc04B & 4.01 & \\
\hline \multirow{5}{*}{ Oc } & Oc01B & 1.09 & \multirow{5}{*}{0.96} & Oc01B & 1.09 & \multirow{5}{*}{0.96} \\
\hline & Oc02B & 0.89 & & Oc02B & 0.89 & \\
\hline & Oc03B & 0.43 & & Oc03B & 0.43 & \\
\hline & Oc04B & 0.72 & & Oc04B & 0.72 & \\
\hline & Oc05B & 1.66 & & Oc05B & 1.66 & \\
\hline
\end{tabular}

Core observations and mechanical tests demonstrate that the pyrite and calcite laminae were often synchronously deposited in natural bedding-parallel fractures. Consequently, the specimens of Cal, Py, Cal-Oc, and Py-Oc mostly had both calcite and pyrite laminae near the center of the discs, and fractures occasionally initiated from or propagated along with their interfaces (Cal-Py) rather than along the designed central laminae, leading to a relatively large fluctuation in the tensile strength of the same lamina types. From the scatter plot of the tensile strength of the Longmaxi Shale with various laminae (see Figure 5), five prominent levels of tensile strength could be easily classified: I (7-8 MPa), II (6-7 MPa), III (5-6 MPa), IV (2-5 MPa), and V (0-2 MPa), corresponding to specimen with Cal, $\mathrm{Py}, \mathrm{Cal}-\mathrm{Oc}, \mathrm{Py}-\mathrm{Oc}$, and Oc, respectively. The results suggest that the strength heterogeneity of shale laminae is apparent, which should be considered for numerical simulation or physical model test design. According to the classification and realignment of the specimens, we recalculated the average tensile strength of each central mineral interlayer type, which were $7.39 \mathrm{MPa}, 6.35 \mathrm{MPa}, 5.47 \mathrm{MPa}$, 3.69 MPa, and 0.96 MPa for shale laminae Cal, Py, Cal-Oc, Py-Oc, and Oc, respectively (Table 1). 


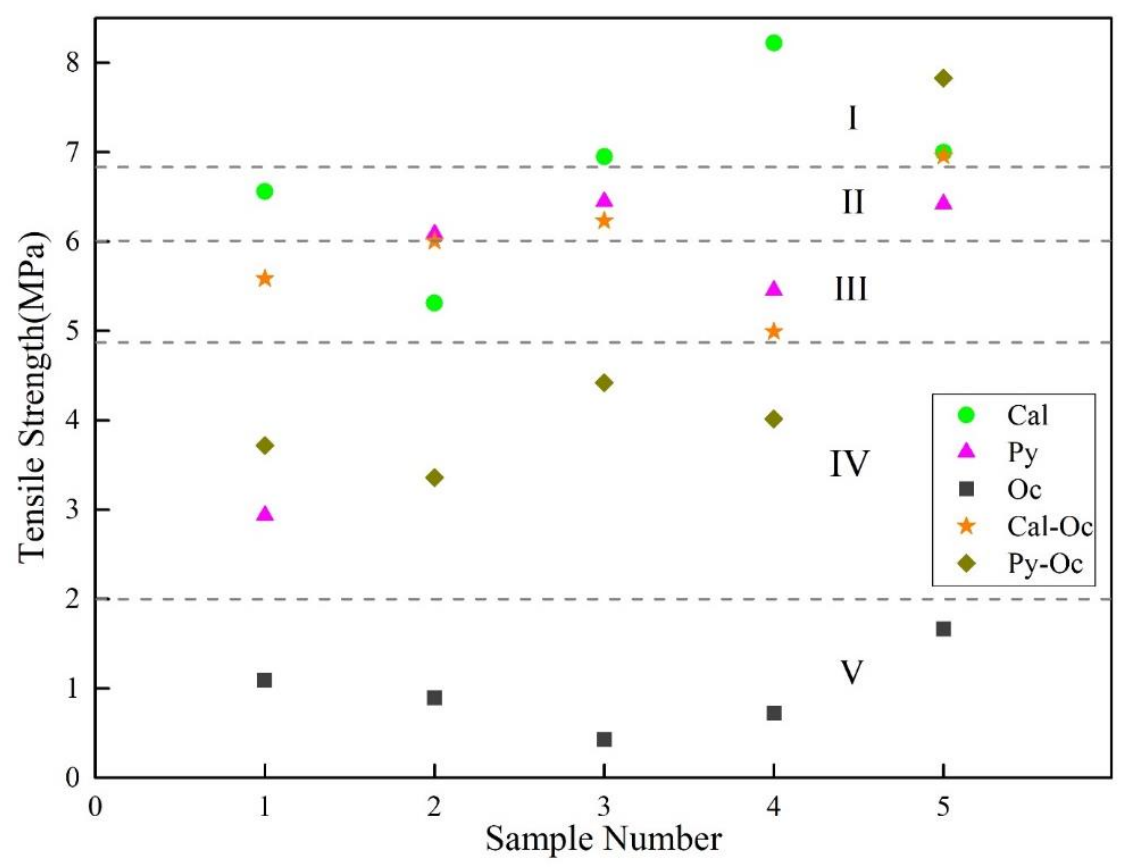

Figure 5. Distribution of Brazilian tensile strength of shale laminae. The tensile strength of the Longmaxi Shale laminae is classified into five levels (I, II, III, IV, V, mainly corresponding to Cal, Py, Cal-Oc, Py-Oc, and Oc, respectively).

\subsection{Shear Strength}

The original test numbers 1-1-1-5, 2-1-2-5, 3-1-3-5, 4-1-4-5, and 5-1-5-5 marked on the cubic samples corresponded to the five sample types with laminae Cal, $\mathrm{Py}, \mathrm{Cal}-\mathrm{Oc}, \mathrm{Py}-\mathrm{Oc}$, and Oc, respectively. Similar to the numbering of discs for the Brazilian tensile test, we substituted the original numbers with Cal01S-05S, Py01S-05S, Cal-Oc01S-05S, Py-Oc01S-05S, and Oc01S-05S.

The shear strength of shale laminae was calculated as follows:

$$
\begin{gathered}
\sigma=P \sin \alpha / A \\
\tau=P \cos \alpha / A
\end{gathered}
$$

where $\sigma$ and $\tau$ are the normal stress and shear stress (MPa), respectively, $P$ is the maximum failure load of the specimen $(\mathrm{N}), \alpha$ is the inclination angle $\left(^{\circ}\right)$, and $A$ is the shear area of the specimen $\left(\mathrm{mm}^{2}\right)$.

The experimental and averaged normal stress and shear stress at various inclination angle obtained during the angle-varied plate shear test is shown in Figure 6. The scatter points represent the stress values of tested samples and the lines are fitted linearly from corresponding points. The fitting formula is characterized as $\tau=\sigma \tan \phi+c$, of which $\tan \phi$ represents the slope of the fitted line and $c$ is the intercept.

To characterize the shear strength characteristics without considering normal stress, the cohesion and internal friction angle of the shale cubes were analyzed according to the linear regression of the normal stress-shear stress curve. As shown in Figure 7 and Table 2, the shear strength parameters of shale laminae have strong heterogeneity due to the difference in mineral components, with a range of 22.50-29.64 MPa for cohesion and 37.29-43.60 for the internal friction angle. The Cal shale laminae had the highest internal friction angle $\left(43.60^{\circ}\right)$ but the lowest cohesion $(22.50 \mathrm{MPa})$. Nevertheless, the specimen with the highest cohesion did not present the smallest internal friction, suggesting that the two parameters were not in a linear negative relation as the mineral components varied. 


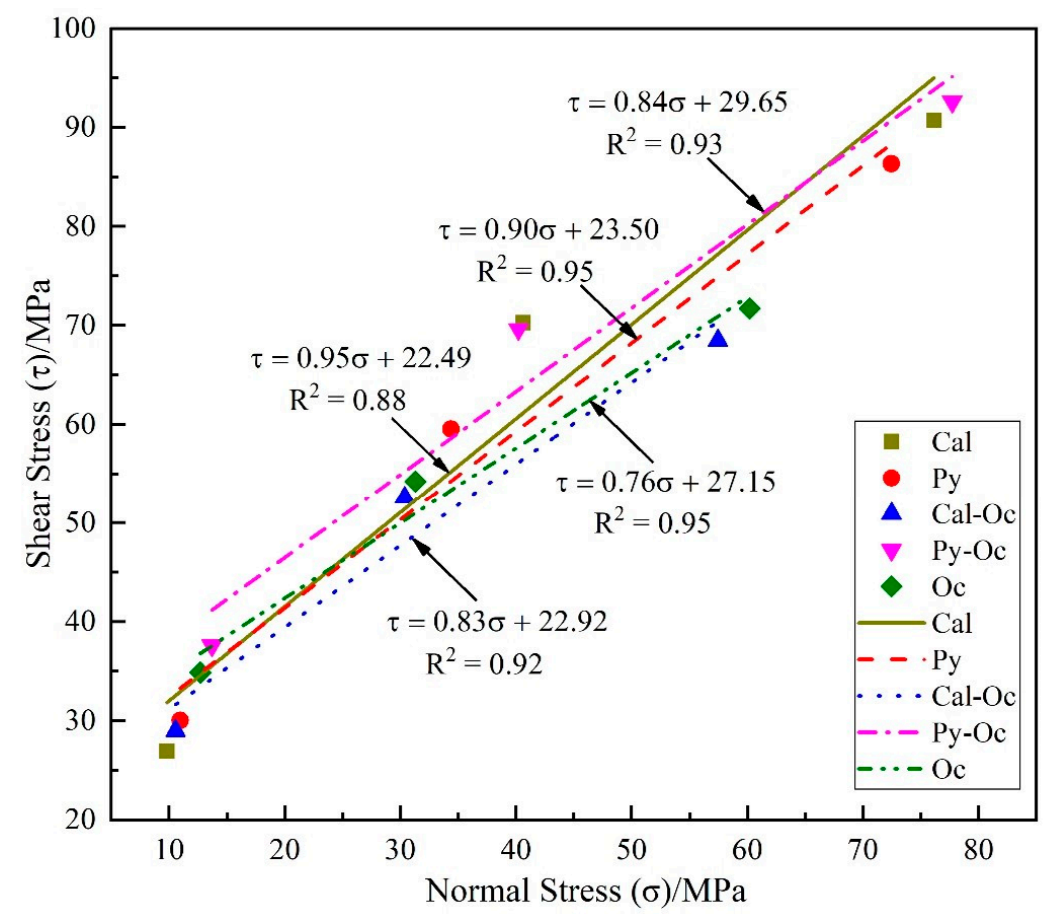

Figure 6. Shear stress and normal stress curve of the Longmaxi Shale laminae under angle-varied plate shear conditions.

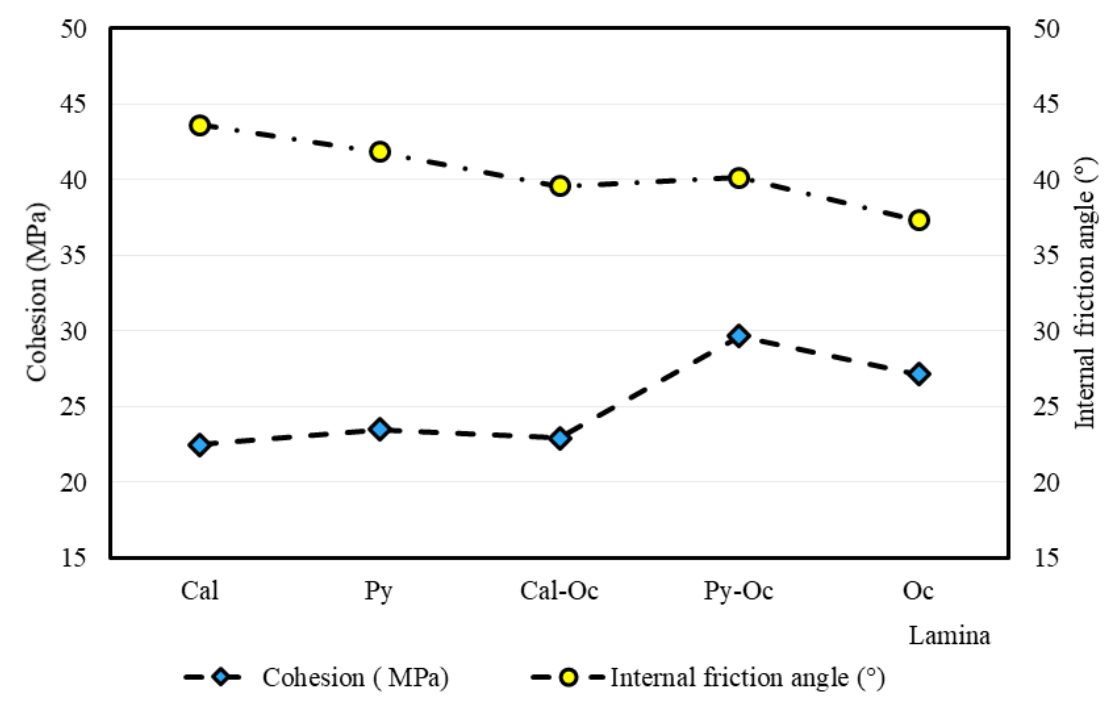

Figure 7. Shear strength parameters for different Longmaxi Shale laminae.

Table 2. Shear strength parameters of the Longmaxi Shale laminae.

\begin{tabular}{cccccc}
\hline Lamina Type & Cal & Py & Cal-Oc & Py-Oc & Oc \\
\hline Cohesion $(\mathrm{MPa})$ & 22.50 & 23.50 & 22.92 & 29.64 & 27.15 \\
Internal friction angle $\left(^{\circ}\right)$ & 43.60 & 41.83 & 39.57 & 40.13 & 37.29 \\
\hline
\end{tabular}

\subsection{Tensile Fracture Morphology}

Test results suggested that the samples with different lamina had different failure modes. We analyzed the potential corresponding relationship between tensile strength and failure morphology, 
and the eventual fracture morphologies of representative specimens were extracted and realigned according to the tensile strength level, as illustrated in Figure 8.

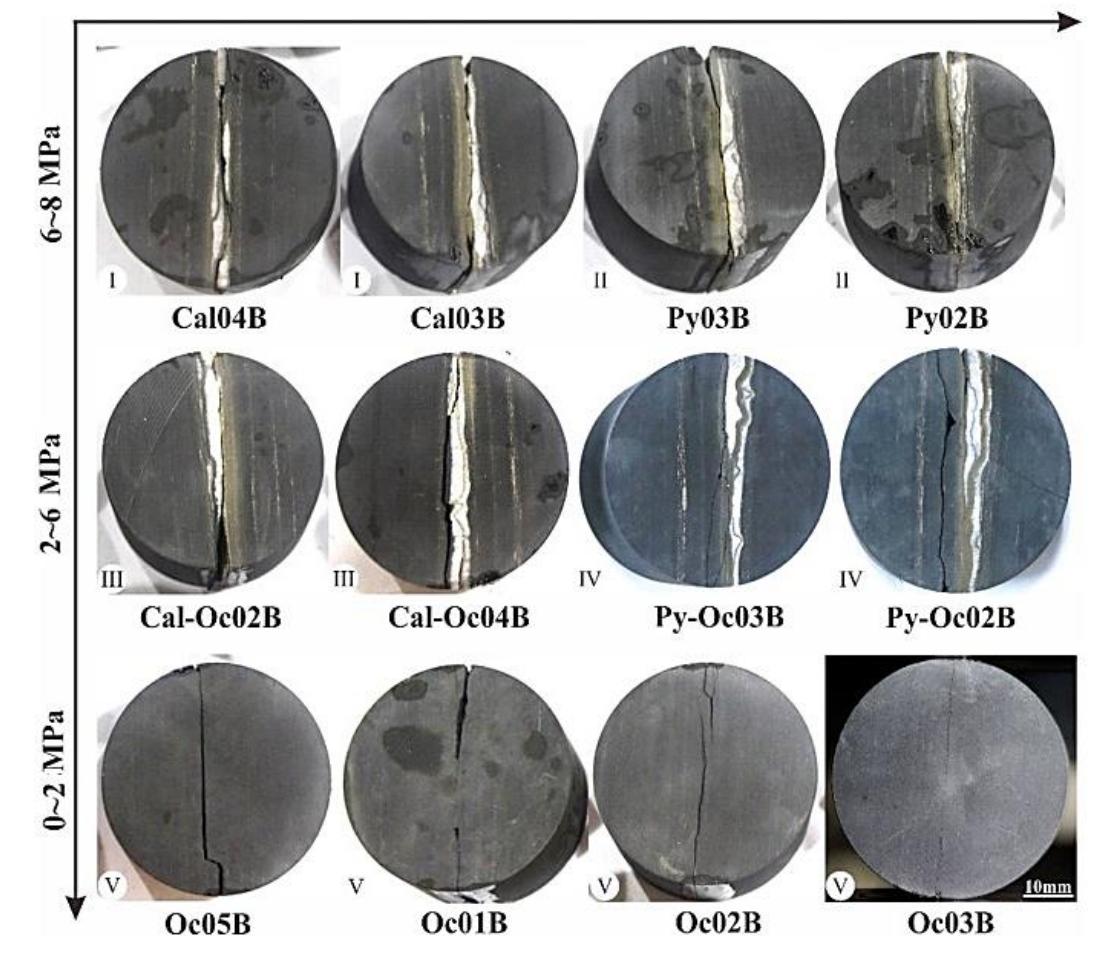

Figure 8. Failure morphology of shale with different laminae crossing the center of Brazilian discs.

As mentioned above, there were five levels $\mathrm{I}-\mathrm{V}$ of tensile strength which could be classified, corresponding to the specimens with Cal, Py, Cal-Oc, Py-Oc, and Oc, respectively. Different laminae had different fracture surfaces. The highest level I failed with tortuous fractures along fluctuations of Cal-Py, while level II tended to fail along the tortuous Cal-Py containing $\sim 1 / 2$ calcite and $\sim 1 / 2$ pyrite. Level III ruptured with straight fractures nearly along Cal-Py or turning from Cal-Py into Py-Oc containing low-density pyrite, while level IV corresponded with fractures turning from straight Cal-Py into Oc or just along Py-Oc containing low-density pyrite. The lowest level V was characterized by straight tension fractures and local shear fractures within organic-enriched laminae (Oc).

Thus, the shale specimens have tensile fractures along with tortuous interfaces and generally consume more energy and have higher tensile strength than those along the linear interfaces. Meanwhile, the larger the contact area of fractures with high content calcite or pyrite lamina, the higher the tensile strength. The eventual failure morphology of shale with various tensile strength and laminae are summarized in Table 3. The tensile strength heterogeneity of the Longmaxi Shale with calcite/pyrite laminae (3.69-7.39 MPa) was similar to the variation of Brazilian tensile strength (3.30-7.63 MPa) of the Marcellus Shale with different anisotropy angles [30], suggesting that the strength heterogeneity was as prominent as the anisotropy of shale. Therefore, the influence of both the mineral difference and bedding orientation should be considered for analyzing the tension behavior of shales. 
Table 3. Tensile strength levels and fracture morphology features of shale with various central laminae.

\begin{tabular}{ccc}
\hline $\begin{array}{c}\text { Brazilian Tensile } \\
\text { Strength Level }\end{array}$ & $\begin{array}{c}\text { Designed Central } \\
\text { Interlayer }\end{array}$ & Fracture Morphology Features \\
\hline I $(7-8 \mathrm{MPa})$ & Cal & Tortuous fractures along fluctuate Cal-Py \\
\hline II $(6-7 \mathrm{MPa})$ & Py & $\begin{array}{c}\text { Tortuous fractures along fluctuate interfaces } \\
\text { consisting of } \sim 1 / 2 \text { Cal-Py and } \sim 1 / 2 \text { Py }\end{array}$ \\
III (5-6 MPa) & Cal-Oc & $\begin{array}{c}\text { Straight fractures nearly along Cal-Py or } \\
\text { Fractures turning from Cal-Py into Py-Oc with } \\
\text { low-density pyrite }\end{array}$ \\
\hline IV $(2-5 \mathrm{MPa})$ & Py-Oc & $\begin{array}{c}\text { Fractures turning from straight Cal-Py into Oc or just } \\
\text { along Py-Oc containing low-density pyrite }\end{array}$ \\
\hline V $(0-2 \mathrm{MPa})$ & Oc & Straight tension fractures and local shear fractures \\
\hline
\end{tabular}

\subsection{Shear Fracture Surface Morphology}

The fracture surface of specimens after shear tests was observed and measured using a high-resolution stereo microscope M205A, trying to interpret the internal mechanism of the shear strength parameter difference due to various laminae. Even though the fracture surfaces were irregular and rugged, high-resolution Montage multi-focus images can be captured by combining the LAS Montage Multi-focus software module with a microscope, with the depth of focus (namely height) recorded synchronously for each pixel in the images.

The maximum field of the microscope was approximately $17 \mathrm{~mm} \times 13 \mathrm{~mm}$, while the specimen surface was about $30 \mathrm{~mm} \times 30 \mathrm{~mm}$. Thus, we took approximately six Montage images for each specimen surface and these were merged into one final picture. The representative pictures of the fracture surfaces with various laminae are exhibited in Figure 9. Fracture surfaces of the organic-enriched laminae seemed to be flattest, while the other four types appeared to fluctuate.
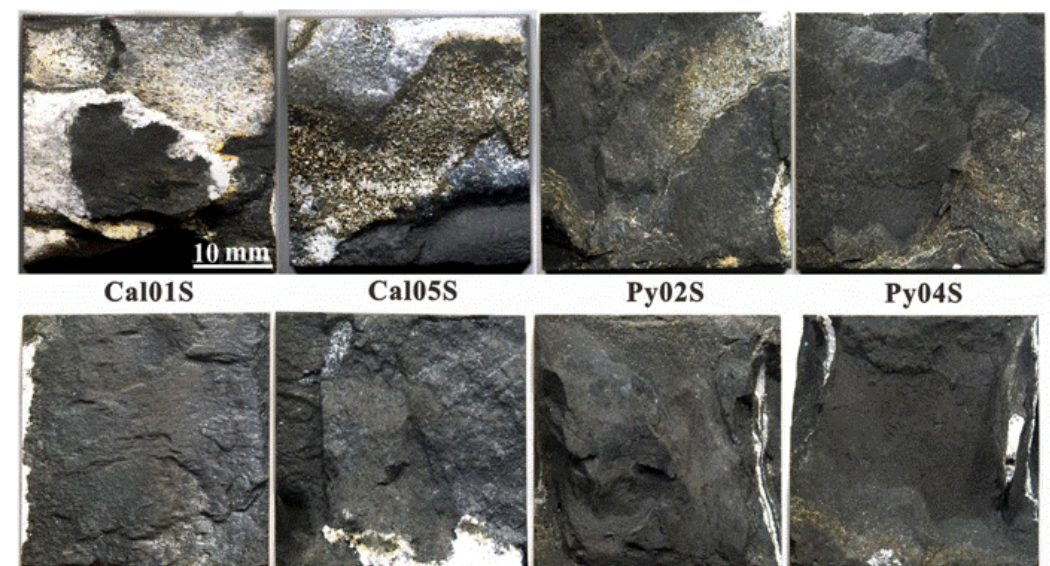

Cal05S

Py02S

Py04S
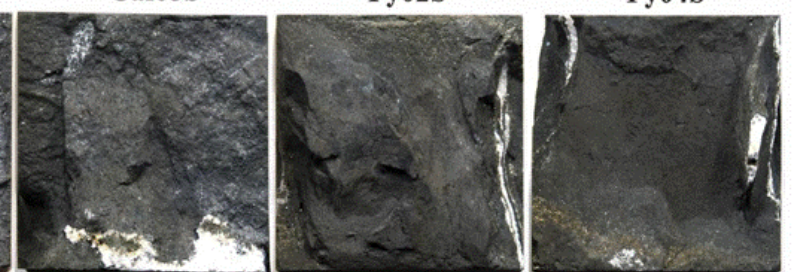

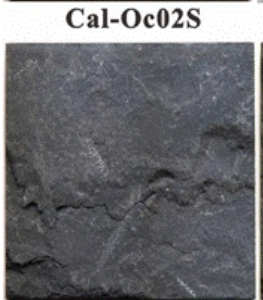

Oc01S
Cal-Oc05S

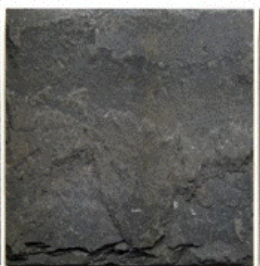

Oc02S
Py-Oc03S

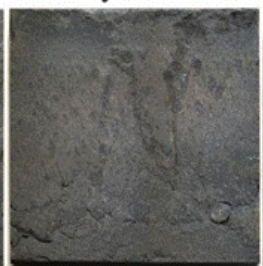

Oc03S
Py-Oc05S

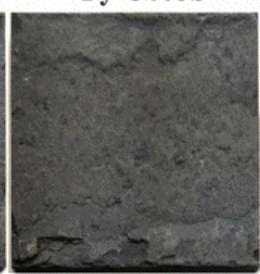

Oc05S

Figure 9. Failure morphology of shale specimen with various laminae after the angle-varied plate shear test. 
Based on the depth of focus recorded for each pixel in the multi-focus images, the statistical analysis of fracture surface roughness was conducted with the cooperation of the Leica Map Start and 3D Viewer software modules. First, the three-dimensional (3D) view of the fracture surface was generated from a two-dimensional (2D) Montage image to reflect the stereo roughness of the shear plane, as shown in Figure 10a,b. The Montages image was then imported into the Leica Map Start to generate the $2 \mathrm{D}$ and 3D depth maps with a depth of focus for each pixel in the image characterized by gradient color (Figure 10c,d). The shades of red represent large values, while those of blue, small values.

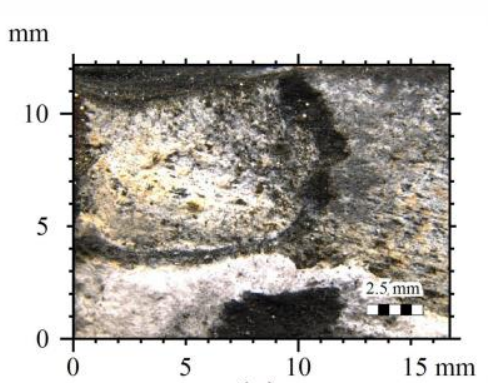

(a)

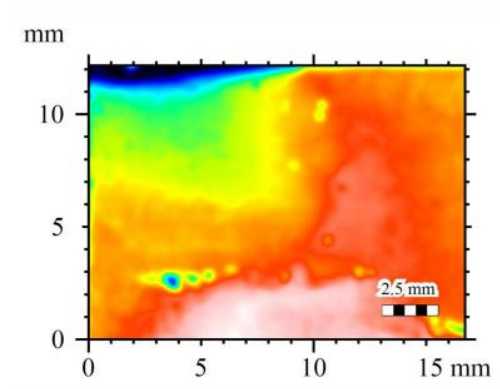

(c)

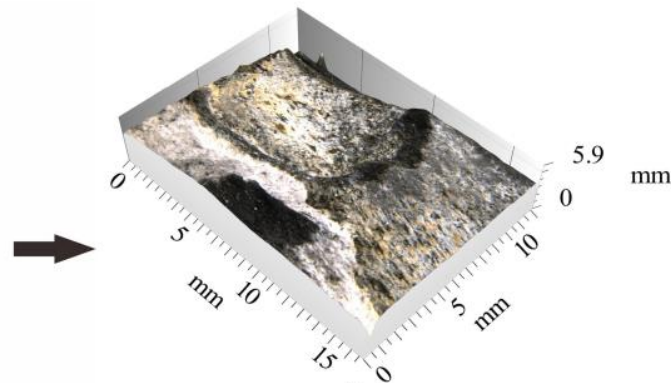

(b)

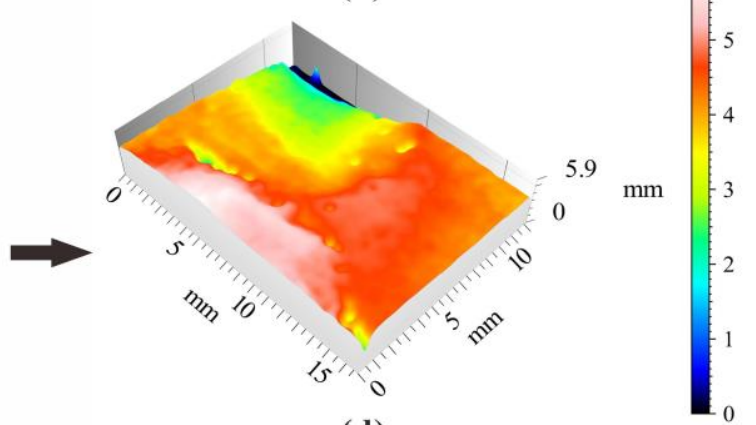

(d) $\mathrm{mm}$

Figure 10. 2D and 3D Montage images of fracture surfaces and corresponding depth maps. (a) 2D Montage image, (b) 3D Montage image, (c) 2D depth map, and (d) 3D depth map.

The fracture surfaces of two representative samples for each lamina type are illustrated in Figure 11, among which the height scales of the corresponding gradient color for shale laminae Py-Oc and Oc were the largest and the smallest, respectively. As the root-mean-square height, namely the standard deviation of the height distribution, is among the most commonly used parameters for characterizing surface roughness [31,32], herein we adopted the root-mean-square height to quantify the surface roughness. The larger value indicates a higher surface roughness. 

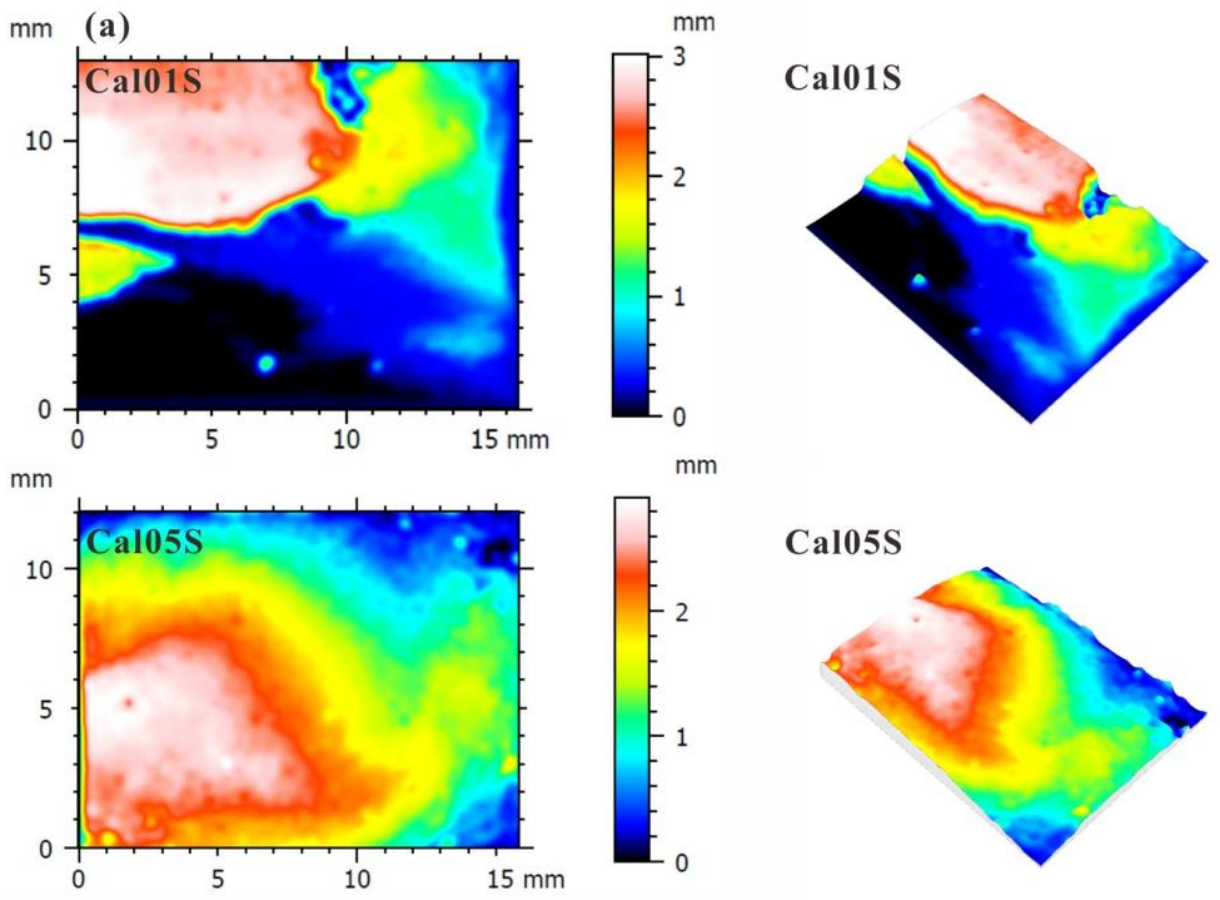

\section{Cal05S}
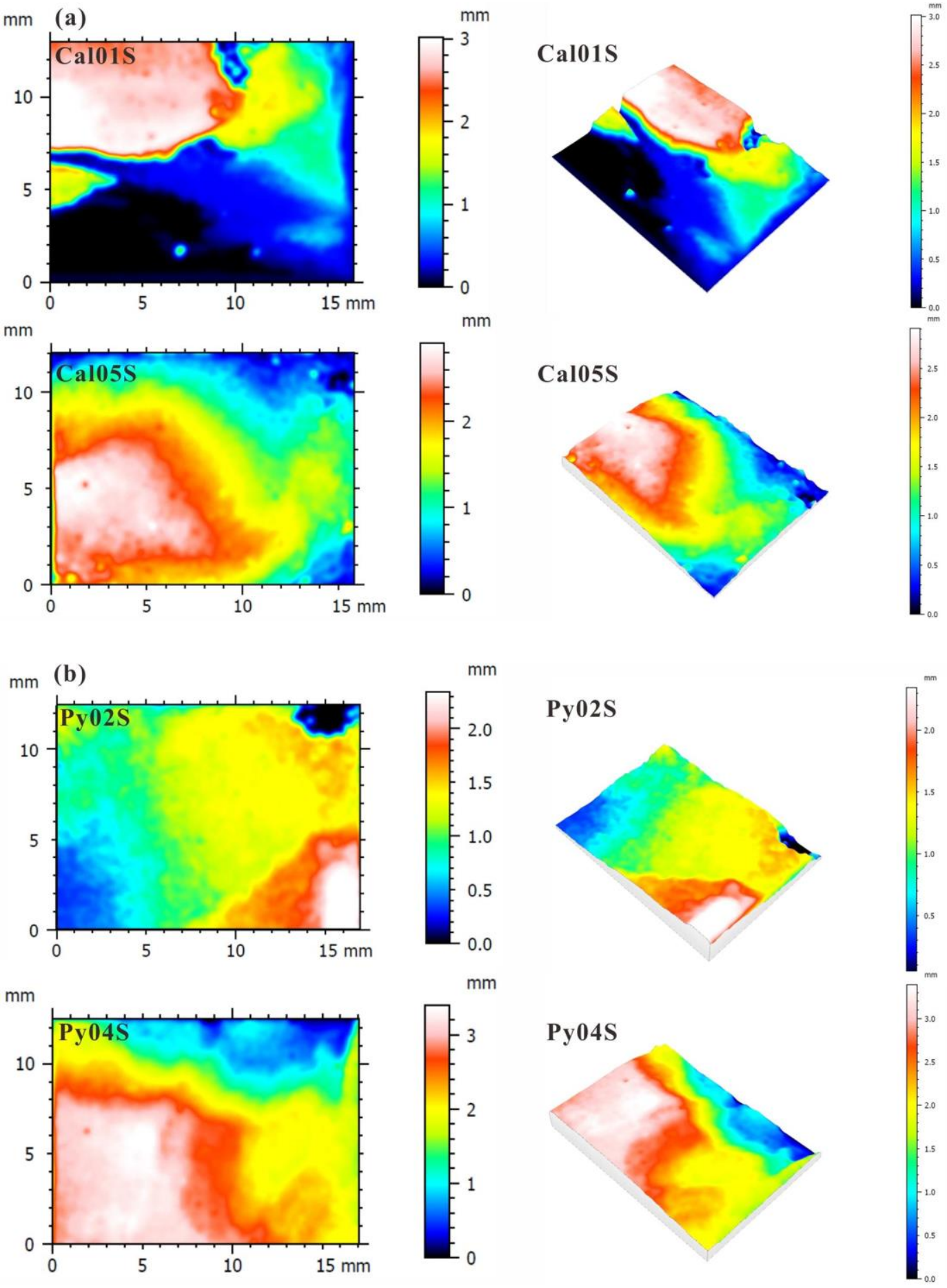

Figure 11. Cont. 
$\mathrm{mm}$ (c)

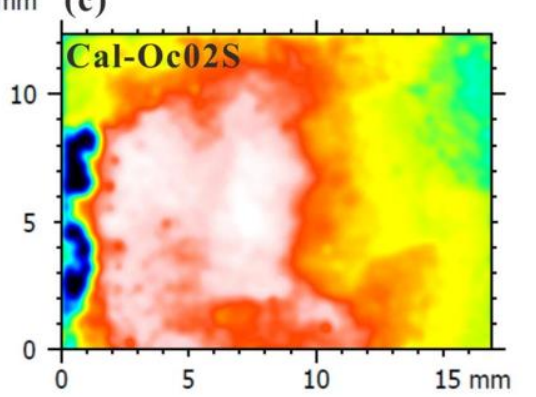

$\mathrm{mm}$

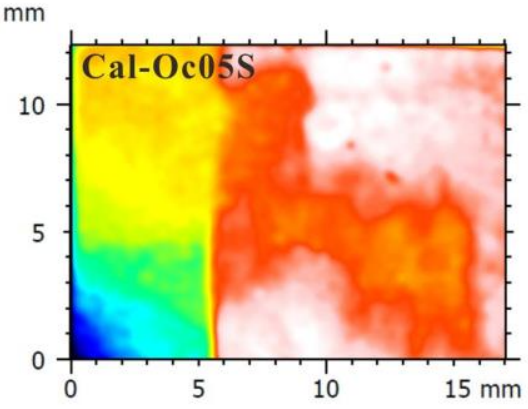

$\mathrm{mm}$ (d)

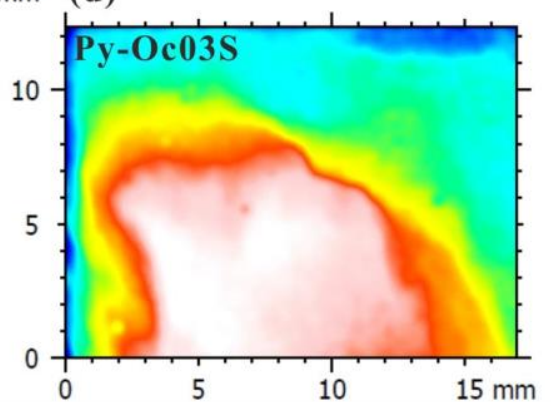

$\mathrm{mm}$

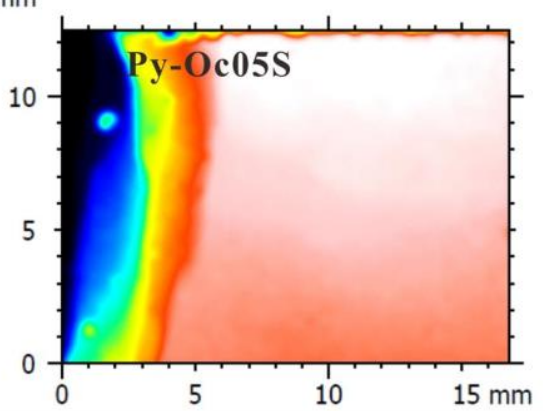

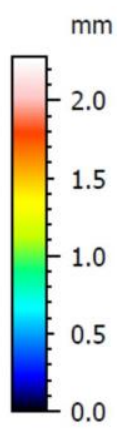

Cal-Oc02S

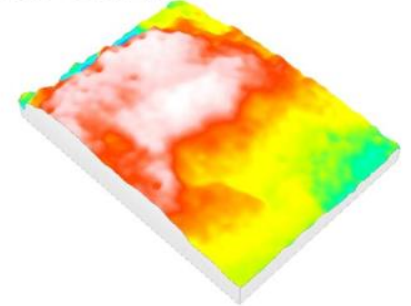

Cal-Oc05S

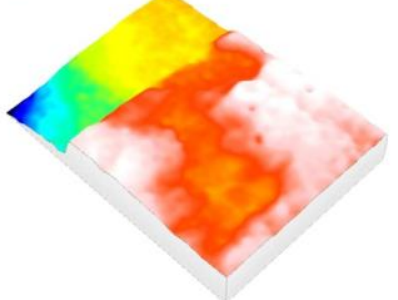

Py-Oc03S

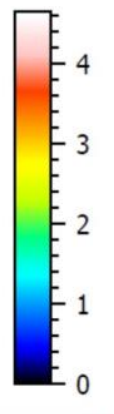

$\mathrm{mm}$

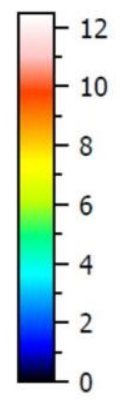

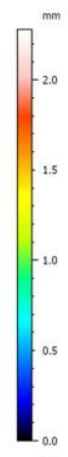
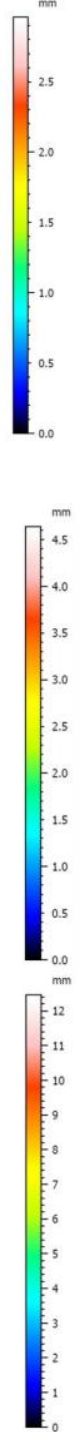

Figure 11. Cont. 

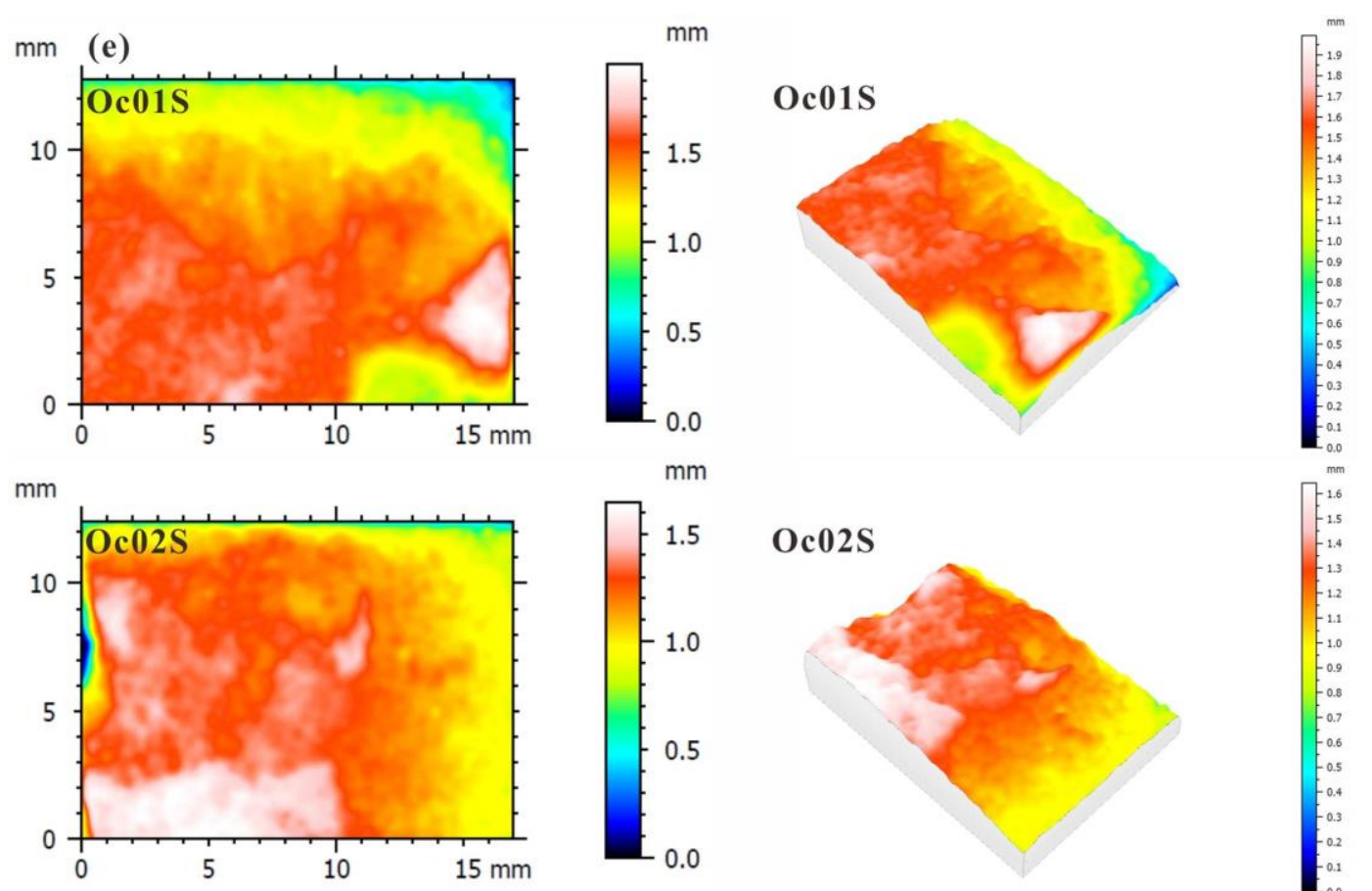

Figure 11. Representative 2D and 3D fracture surface roughness after the angle-varied plate shear test. The sample number is given at the top-left of each image. (a-e) corresponds to the shale laminae of Cal, Py, Cal-Oc, Py-Oc, and Oc respectively.

The root-mean-square height formula is included in the ISO 25178 standard as follows:

$$
S_{q}=\sqrt{\frac{1}{A} \iint z^{2}(x, y) d x d y}
$$

where $A$ is the projected area of the fracture surface and $z$ is the height perpendicular to the surface, namely the depth of focus, which is the function of horizontal and vertical coordinates $x$ and $y$.

Since the final fracture surface of each specimen after the angle-varied plate shear test was merged from several sub-images, the root-mean-square height of each specimen was calculated based on the corresponding roughness of sub-images. Hence, first, the root-mean-square of each sub-image was calculated with the depth of focus of numerous pixels (with a pixel resolution of $2560 \times 1920$ ) on the image. The root-mean-square height of each specimen was then obtained by averaging the value of its sub-images. Finally, fracture surface roughness was characterized quantitatively with the average root-mean-square height of five parallel specimens of each type, as summarized in Table 4 . The results indicated that the fracture surfaces of shale lamina Py-Oc were the roughest, while the fracture plane of shale lamina Oc was the smoothest. We infer that the largest roughness of shear planes along the interfaces of pyrite and organic-enriched laminae could be attributed to the largest strength difference between pyrite and organic matters. As we compared the fracture surface roughness parameter with shear strength parameters, good consistency was revealed between the variation of cohesion and the fracture roughness due to the mineral composition of the laminae (see Figure 12). In other words, the larger the cohesion, the rougher the fracture surface. This finding could shed light on the optimization of shear fracture roughness according to the features of shear strength parameters.

Table 4. Variation in fracture surface roughness parameters of the Longmaxi Shale laminae.

\begin{tabular}{cccccc}
\hline Lamina Type & Cal & Py & Cal-Oc & Py-Oc & Oc \\
\hline Fracture surface roughness $(\mathrm{mm})$ & 0.58 & 0.67 & 0.56 & 1.09 & 0.26 \\
\hline
\end{tabular}




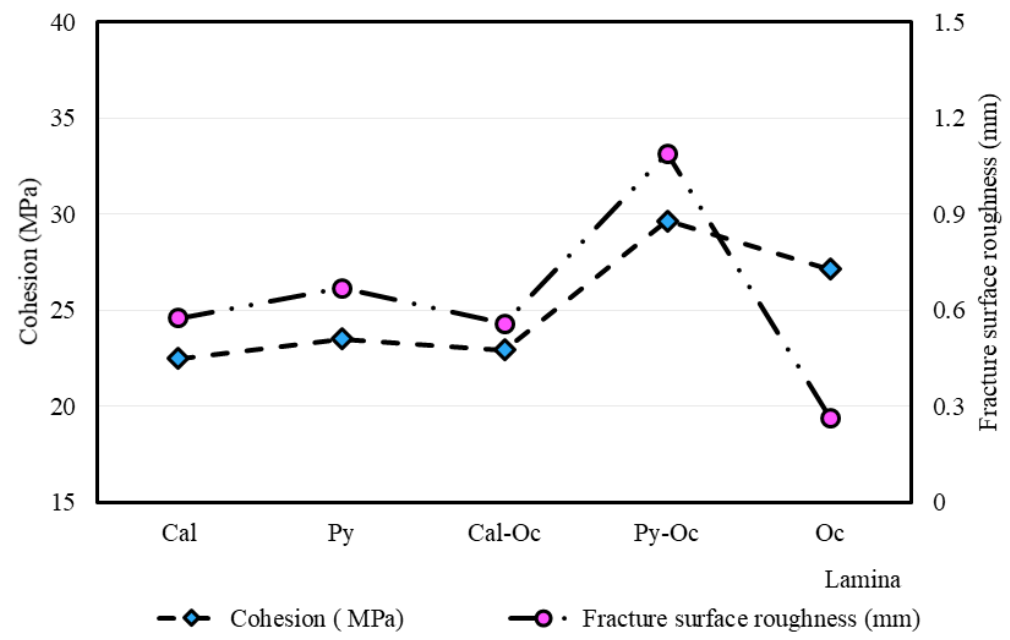

Figure 12. Cohesion and fracture surface roughness variation curve with different laminae.

\section{Discussion}

This study found that pyrite laminae were commonly associated with calcite and that their association had a great influence on the fracture modes of shale. As the fracture position of the sample in shear tests was controllable and the test results revealed the strength of each lamina type, herein we analyze only the tensile test results.

Figure 13 shows the association development of pyrite lamina and calcite lamina (upper part) and their broken features after tests (bottom part). As shown in the figure, there were three association types of pyrite and calcite laminae. First, pyrite lamina was embedded in the calcite lamina; second, pyrite developed tightly adjacent to the calcite lamina; and third, the first and second types developed together and coexisted.
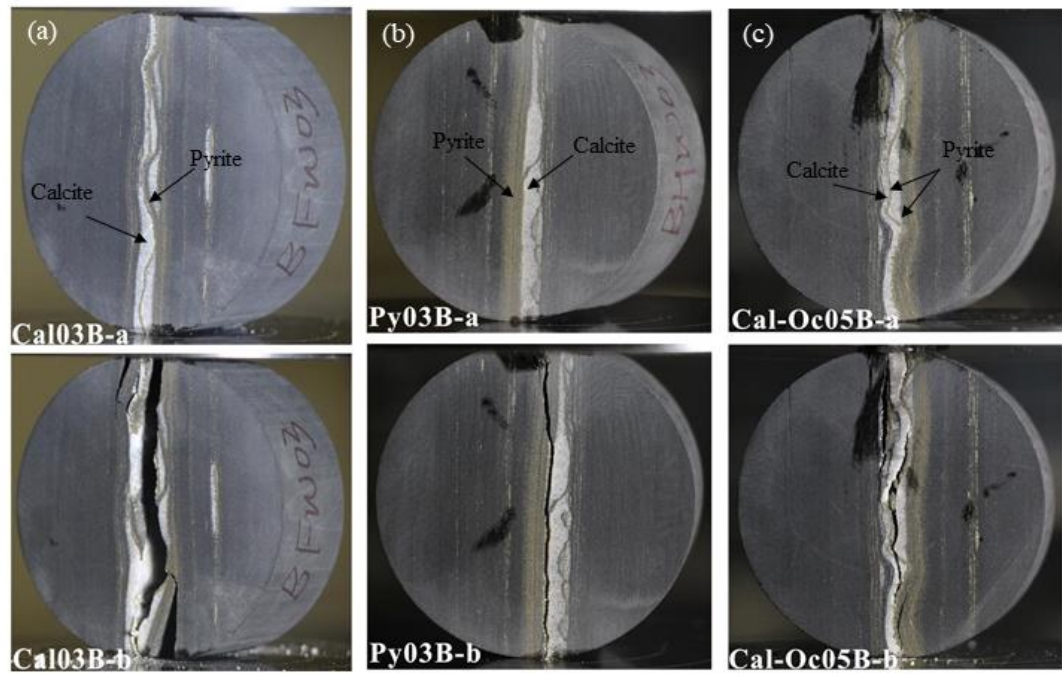

Figure 13. Association development of pyrite lamina and calcite lamina and their broken pictures.

(a) pyrite lamina embedded in calcite lamina; (b) pyrite developed tightly adjacent to calcite lamina;

(c) pyrite lamina embedded in and adjacent to calcite lamina.

Figure 13a shows the typical discs with central calcite laminae (Cal), with the tensile fracture having mainly occurred in the calcite lamina crossing the pyrite lamina that it was embedded in. These specimens were relatively brittle such that four in five specimens broke with half-discs falling down to the bearing plate, likely due to the relatively large energy release within a short time period. 
Figure $13 \mathbf{b}$ demonstrates that the fracture was captured by the interface between pyrite and calcite laminae, although the fracturing began in the pyrite lamina in the upper part. Compared with Cal discs, the broken behaviors of Py discs were relatively gentle, with only one specimen having failed with a half-disc thrown to the ground. While in Figure 13c, the fracture occurred along the tortuous pyrite lamina embedded in calcite lamina, showing various tensile strengths due to the variation of pyrite content and the occurrence of the interface.

Our experimental results are in good agreement with that the fracture patterns impacted by bedding planes and calcite veins under the Brazilian tensile test $[17,33,34]$. Generally, for the shale loaded parallel to the bedding plane, the diametrical tensile fracture initiates in the middle region but does not follow a single layer or bedding plane and is also not perfectly straight but slightly curved [33]. When the contained calcite-filled discontinuities are along the applied force or crossed with small angle, the discontinuities are easy to activate and tensile failure mainly occurs along them [17]. However, different from the profoundly reduced tensile strength of shale with sealed fractures or calcite veins, nearly half of the sample without the fractures or veins [34,35], the tensile strength of shale containing calcite laminae in our tests are measured to be much higher than the shale solely composed with organic-rich laminae, as we have demonstrated in Table 1 and Figure 5. The probable reason for it is that the thickness of mineral laminae in our tests, approximately $1.5-4.0 \mathrm{~mm}$, is much larger than the veins or sealed fractures, about $0.17 \mathrm{~mm}$ by Mighani et al. [34]. Consequently, the thicker calcite laminae have coarser crystal grains and the interface between calcite laminae and organic-rich matrix is a strong bond rather than a plane of weakness indicated by Padin et al. [36]. Overall, the fracture modes and tensile strength differences show that the calcite laminae have a great influence on the tensile fracture of shale. The geometry and the mechanical properties of calcite laminae should be taken into consideration during the design of shale gas exploration. The mechanical behavior of shale laminae in this study is mainly based on laboratory uniaxial tests on natural shale rocks. Integrating by experimental studies and numerical simulations, the future investigations on this topic mainly focus on the mechanical properties of shale laminae under various fracturing conditions, the process detection of crack initiation, propagation, and eventual failure during mechanical tests of shale laminae, and the in-situ mechanical response of shale laminae to fracturing in field-scale. These further research achievements would provide more optimization data of fracturing design for shale gas exploitation.

\section{Conclusions}

This paper presents a series of Brazilian tensile tests and angle-varied plate shear tests on the Longmaxi Shale to investigate the mechanical properties of shale laminae. With the mechanical strength and corresponding fracture surface morphology characterization, the main understandings of the tension and shear behavior of the Longmaxi Shale laminae are summarized as follows:

(1) Tensile strength of the Longmaxi Shale laminae fluctuated over five levels: I (7-8 MPa), II (6-7 MPa), III (5-6 MPa), IV (2-5 MPa), and V (0-2 MPa), mainly corresponding to the laminae Cal, Py, Cal-Oc, Py-Oc, and Oc, respectively.

(2) Shear strength parameters ranged from 22.50-29.64 MPa for cohesion and 37.29-43.60 for internal friction angle. The cohesion was strongly related to the fracture surface roughness of different laminae.

(3) According to the fracture modes, the calcite laminae have a high influence on the tensile fracturing of shale. Our study suggests that the geometry and the properties of calcite laminae should receive more attention during the design of shale gas exploration.

Author Contributions: Conceptualization, L.L.; methodology, L.L.; validation, X.H. and M.W.; formal analysis, B.H. and M.W.; investigation, B.H.; writing-original draft preparation, B.H.; writing-review and editing, L.L.; supervision, L.L.; project administration, X.L.; funding acquisition, X.L. All authors have read and agreed to the published version of the manuscript. 
Funding: This research was funded by the National Natural Science Foundation of China (nos. 41977248, 41641025) and the Strategic Priority Research Program of the Chinese Academy of Sciences (no. XDB10030101).

Acknowledgments: The authors thank Shengwen Qi from the Institute of Geology and Geophysics, CAS, for his comments on the manuscript.

Conflicts of Interest: The authors declare no conflict of interest.

\section{References}

1. Ilgen, A.G.; Heath, J.E.; Akkutlu, I.Y.; Bryndzia, L.T.; Cole, D.R.; Kharaka, Y.K.; Kneafsey, T.J.; Milliken, K.L.; Pyrak-Nolte, L.J.; Suarez-Rivera, R. Shales at all scales: Exploring coupled processes in mudrocks. Earth Sci. Rev. 2017, 166, 132-152. [CrossRef]

2. Lei, Y.; Luo, X.; Wang, X.; Zhang, L.; Jiang, C.; Yang, W.; Yu, Y.; Cheng, M.; Zhang, L. Characteristics of silty laminae in Zhangjiatan Shale of southeastern Ordos Basin, China: Implications for shale gas formation. AAPG Bull. 2015, 99, 661-687. [CrossRef]

3. Rokosh, D.; Pawlowicz, J.; Anderson, S.; Berhane, M.; Beaton, A. Shale fabric, mineralogy and effective porosity of the Upper Colorado Group. In Frontiers +Innovation; Alberta CSPG CSEG CWLS Convention: Calgary, AB, Candada, 2009; pp. 572-576.

4. Na, S.; Sun, W.; Ingraham, M.D.; Yoon, H. Effects of spatial heterogeneity and material anisotropy on the fracture pattern and macroscopic effective toughness of Mancos Shale in Brazilian tests. J. Geophys. Res. Solid Earth 2017, 122, 6202-6230. [CrossRef]

5. Li, H.; Lai, B.; Liu, H.-H.; Zhang, J.; Georgi, D. Experimental Investigation on Brazilian Tensile Strength of Organic-Rich Gas Shale. SPE J. 2017, 22, 148-161. [CrossRef]

6. Chen, L.; Lu, Y.; Jiang, S.; Li, J.; Guo, T.; Luo, C. Heterogeneity of the Lower Silurian Longmaxi marine shale in the southeast Sichuan Basin of China. Mar. Pet. Geol. 2015, 65, 232-246. [CrossRef]

7. Dong, T.; Harris, N.; Ayranci, K.; Twemlow, C.E.; Nassichuk, B.R. Porosity characteristics of the Devonian Horn River shale, Canada: Insights from lithofacies classification and shale composition. Int. J. Coal Geol. 2015, 141, 74-90. [CrossRef]

8. Rybacki, E.; Meier, T.; Dresen, G. What controls the mechanical properties of shale rocks?-Part II: Brittleness. J. Pet. Sci. Eng. 2016, 144, 39-58. [CrossRef]

9. Rickman, R.; Mullen, M.J.; Petre, J.E.; Grieser, W.V.; Kundert, D. A practical use of shale petrophysics for stimulation design optimization: All shale plays are not clones of the Barnett Shale. In Proceedings of the SPE Annual Technical Conference and Exhibition, Denver, CO, USA, 1 January 2008; pp. 1-11. [CrossRef]

10. Eliyahu, M.; Emmanuel, S.; Day-Stirrat, R.J.; Macaulay, C.I. Mechanical properties of organic matter in shales mapped at the nanometer scale. Mar. Pet. Geol. 2015, 59, 294-304. [CrossRef]

11. Kumar, V.; Sondergeld, C.H.; Rai, C.S. Nano to Macro Mechanical Characterization of Shale. In Proceedings of the SPE Annual Technical Conference and Exhibition, San Antonio, TX, USA, 1 January 2012; pp. 1-23. [CrossRef]

12. Sone, H.; Zoback, M.D. Mechanical properties of shale-gas reservoir rocks-Part 1: Static and dynamic elastic properties and anisotropy. Geophysics 2013, 78, D381-D392. [CrossRef]

13. Alqahtani, A.A.; Mokhtari, M.; Tutuncu, A.N.; Sonnenberg, S. Effect of Mineralogy and Petrophysical Characteristics on Acoustic and Mechanical Properties of Organic Rich Shale. In Proceedings of the Unconventional Resources Technology Conference, Denver, CO, USA, 12-14 August 2013; pp. 399-411. [CrossRef]

14. Dong, N.B.H.T.; Yang, S. The impact of rock composition on geomechanical properties of a shale formation: Middle and Upper Devonian Horn River Group shale, Northeast British Columbia, Canada. AAPG Bull. 2017, 101, 177-204. [CrossRef]

15. Qin, X.; Wang, Z.; Yu, H.; Chen, H.; Lei, Y.; Luo, X.; Zhang, L.; Jiang, C.; Gao, C. A new shale brittleness evaluation method based on rock physics and mineral compositions. Nat. Gas Geosci. 2016, 27, 1924-1932.

16. Vervoort, A.; Min, K.-B.; Konietzky, H.; Cho, J.-W.; Debecker, B.; Dinh, Q.-D.; Frühwirt, T.; Tavallali, A. Failure of transversely isotropic rock under Brazilian test conditions. Int. J. Rock Mech. Min. Sci. 2014, 70, 343-352. [CrossRef] 
17. Mokhtari, M.; Bui, B.T.; Tutuncu, A.N. Tensile Failure of Shales: Impacts of Layering and Natural Fractures. In Proceedings of the SPE Western North American and Rocky Mountain Joint Meeting, Denver, CO, USA, 17-18 April 2014; Society of Petroleum Engineers: Denver, CO, USA, 2014; p. 23. [CrossRef]

18. Tan, J.; Horsfield, B.; Fink, R.; Krooss, B.; Schulz, H.-M.; Rybacki, E.; Zhang, J.; Boreham, C.J.; Van Graas, G.; Tocher, B.A. Shale Gas Potential of the Major Marine Shale Formations in the Upper Yangtze Platform, South China, Part III: Mineralogical, Lithofacial, Petrophysical, and Rock Mechanical Properties. Energy Fuels 2014, 28, 2322-2342. [CrossRef]

19. Cheng, Y.; Wong, L.N.Y. Microscopic Characterization of Tensile and Shear Fracturing in Progressive Failure in Marble. J. Geophys. Res. Solid Earth 2018, 123, 204-225. [CrossRef]

20. Huang, X.; Haimson, B.; Plesha, M.; Qiu, X. An investigation of the mechanics of rock joints-Part I. Laboratory investigation. Int. J. Rock Mech. Min. Sci. Géoméch. Abstr. 1993, 30, 257-269. [CrossRef]

21. Bahaaddini, M.; Hagan, P.; Mitra, R.; Khosravi, M.H. Experimental and numerical study of asperity degradation in the direct shear test. Eng. Geol. 2016, 204, 41-52. [CrossRef]

22. Price, D.G.; de Freitas, M.; Hack, H.; Higginbottom, I.E.; Knill, J.L.; Maurenbrecher, M. Engineering Geology: Principles and Practice; Springer: Berlin/Heidelberg, Germany, 2009; p. 450.

23. Abousleiman, Y.N.; Hoang, S.K.; Tran, M.H. Mechanical characterization of small shale samples subjected to fluid exposure using the inclined direct shear testing device. Int. J. Rock Mech. Min. Sci. 2010, 47, 355-367. [CrossRef]

24. Frash, L.P.; Carey, J.W.; Lei, Z.; Rougier, E.; Ickes, T.; Viswanathan, H.S. High-stress triaxial direct-shear fracturing of Utica shale and in situ X-ray microtomography with permeability measurement. J. Geophys. Res. Solid Earth 2016, 121, 5493-5508. [CrossRef]

25. Chen, J.; Lan, H.; Macciotta, R.; Wu, Y.; Li, Q.; Zhao, X. Anisotropy rather than transverse isotropy in Longmaxi shale and the potential role of tectonic stress. Eng. Geol. 2018, 247, 38-47. [CrossRef]

26. Lyu, Q.; Long, X.; Ranjith, P.; Tan, J.; Kang, Y. Experimental investigation on the mechanical behaviours of a low-clay shale under water-based fluids. Eng. Geol. 2018, 233, 124-138. [CrossRef]

27. ISRM. Suggested methods for determining tensile strength of rock materials. Int. J. Rock Mech. Min. Sci. Geomech. Abstr. 1978, 15, 99-103.

28. Tan, X.; Konietzky, H.; Frühwirt, T.; Dan, D.Q. Brazilian Tests on Transversely Isotropic Rocks: Laboratory Testing and Numerical Simulations. Rock Mech. Rock Eng. 2014, 48, 1341-1351. [CrossRef]

29. Li, W.; Jin, C.; Cusatis, G. Integrated Experimental and Computational Characterization of Shale at Multiple Length Scales. In New Frontiers in Oil and Gas Exploration; Springer International Publishing AG: Cham, Switzerland, 2016; pp. 389-434.

30. Jin, Z.; Li, W.; Jin, C.; Hambleton, J.; Cusatis, G. Anisotropic elastic, strength, and fracture properties of Marcellus shale. Int. J. Rock Mech. Min. Sci. 2018, 109, 124-137. [CrossRef]

31. Kassis, S.; Sondergeld, C.H. Fracture Permeability of Gas Shale: Effect of Roughness, Fracture Offset, Proppant, and Effective Stress. In Proceedings of the International Oil and Gas Conference and Exhibition in China, Beijing, China, 1 January 2010; p. 17.

32. Thomas, T. Characterization of surface roughness. Precis. Eng. 1981, 3, 97-104. [CrossRef]

33. Simpson, N.D.J.; Stroisz, A.; Bauer, A.; Vervoort, A.; Holt, R.M. Failure Mechanics of Anisotropic Shale During Brazilian Tests. In Proceedings of the 48th U.S. Rock Mechanics/Geomechanics Symposium, Minneapolis, MN, USA, 18 August 2014; p. 13.

34. Mighani, S.; Sondergeld, C.H.; Rai, C. Observations of Tensile Fracturing of Anisotropic Rocks. SPE J. 2016, 21, 1289-1301. [CrossRef]

35. Gale, J.; Reed, R.M.; Holder, J. Natural fractures in the Barnett Shale and their importance for hydraulic fracture treatments. AAPG Bull. 2007, 91, 603-622. [CrossRef]

36. Padin, A.; Tutuncu, A.N.; Sonnenberg, S. On the Mechanisms of Shale Microfracture Propagation. In Proceedings of the SPE Hydraulic Fracturing Technology Conference, The Woodlands, TX, USA, 4-6 February 2014.

(C) 2020 by the authors. Licensee MDPI, Basel, Switzerland. This article is an open access article distributed under the terms and conditions of the Creative Commons Attribution (CC BY) license (http://creativecommons.org/licenses/by/4.0/). 